\title{
Favorable Psychological Characteristics of Preschool Children when Learning English as a Second Language
}

\author{
Nhut Minh Tran ${ }^{1}$ and Trang Thi Minh $L y^{2}$ \\ ${ }^{1}$ Faculty of Education, An Giang University, An Giang, Vietnam \\ Vietnam National University - Ho Chi Minh City, Vietnam \\ ${ }^{2}$ Faculty of Foreign Languages, An Giang University, An Giang, Vietnam \\ Vietnam National University - Ho Chi Minh City, Vietnam
}

\begin{abstract}
Currently, teaching and learning English for children as a second language is a matter of social concern. At what age is it appropriate to start teaching English to children, how to approach to achieve high efficiency is being studied by psychologists, educational administrators and educational institutions for children.Through the research problem, the author has pointed out the favorable psychological characteristics of preschool children when learning English and more, on the basis of research on age psychology, pedagogical psychology and practice teaching in preschool, the author has proposed measures to help 5-year-old children learn English as a second language effectively. Accordingly, it is necessary to make conclusions and recommendations for students' parents, teachers, educational administrators, etc. to contribute to creating opportunities for children to approach English in the best way.
\end{abstract}

Keywords:favorable psychological characteristics, preschool children, English as a second language,English teaching.

\section{Introduction}

English is a global language, an indispensable tool for each country in the process of international integration. Currently, English has become the most popular and widely used language in the world. Around the world, there are nearly 60 countries where English is the main language, besides the mother tongue, and nearly 100 countries use English as a second language. Knowing how to use English fluently as a second language after the mother tongue is an advantage in personal development and brings success to each person as an adult. In Vietnam, introducing children to English right from preschool is currently attracting the attention of scientists, educators and parents. Based on the results of scientific research on child psychology, the practice of teaching and learning English in some Southeast Asian countries and the results of pilot implementation for children to become acquainted with English in some countries. Early childhood education institutions in recent years have pointed out the necessity, suitability and effectiveness of giving children early access to English from preschool age, especially 5-year-old children.

Organizing for children to learn and get acquainted with English right from preschool should be considered as one of the solutions to improve the quality of comprehensive education, ensure the inheritance as well as create a solid premise for children to learn. English at the high school level, contributing to meeting the requirements of highquality human resources in the integration period. This is also the general development trend of modern education, also part of the goal of early childhood education.

However, organizing children to familiarize themselves with English is not an easy task. It requires seriousness and science from determining the starting age, the purpose of learning to the compliance with the necessary conditions in terms of qualifications, foreign language ability, teacher's pedagogy, about facilities, program content as well as quality control inspection... Clearly distinguish the purpose of English familiarization in preschool children from high school students and strictly adhere to relevant conditions. It is important to make a decisive contribution to ensuring the success of the process of introducing children to English in preschool. 


\section{Review of Literature}

\subsection{Psychological characteristics of 3 to 5- year-old children}

\subsubsection{Children's learning activities}

According to research by psychologists, learning activity in preschool children is still "Learning to play, playing to learn". Learning in the sense of playing in a sequence of actions similar to learning, because the design of "Learning to play" shows: the learning content is both gentle and attractive to children, the objects of the "class" are the specific and intuitive knowledge.

The learning process take place similar to the class, but not as rigorous and stressful as the class. But the class still has enough steps to advance to class such as: organizing the class, conducting the lesson (leading to the lesson, asking questions, explaining concepts), ending the lesson by letting the children repeat the concepts they have learned (consolidate the lesson). The psychological functions that take place in the "classroom" are the same as those in the first grade, students must pay attention to listen to her instructions and explanations, use memory forms, and think operations according to the class requirements. Consciousness is mobilized to the maximum to understand the lesson.

The friendship relationship in "Learning and playing" is also established almost like the friendship relationship in the first grade, the relationship between her and the child is similar to that of a teacher and a student in the first grade, meaning that she can "stand" to teach but can also sit with children to explain, analyze and prove. Teacher's language is both coherent, clear and expressive, especially in the subject of stories, poems... and pictures, pictures...

The "sessions" of learning music, visual arts, etc. have aroused real interest in learning for children. Children learn to familiarize themselves with the lessons to acquire simple knowledge that is close to children, but is a premise for children to enter first grade. Children gradually become aware of their learning tasks, duties and responsibilities of what students have to do to please their teachers and beloved friends.

\subsubsection{Children's attention development}

Many children's attentional qualities have been developed, children know how to direct their consciousness to objects needed for play, study or self-service work.

Children have the ability to pay attention intentionally from 37 to 51 minutes, the object of attention is attractive and varied, stimulating the children's curiosity and curiosity.

Children can distribute attention to 2,3 objects at the same time, but the time of attention
ISSN 2455-6378

distribution is not stable and easily fluctuating. Move the child's attention quickly, if the instruction moves well. Distracted attention in children is still strong, sometimes children cannot control themselves due to instinctive impulses. Therefore, it is necessary to change toys and games more attractive.

At this stage, the meaning of the sound makes the child pay much attention. From outside sounds, children know how to focus on thoughts and feelings inside their brains.

It is necessary to practice the qualities of attention for children through games and lessons.

\subsubsection{The language development of 3 to 5-year- old children}

At this age, children use their mother tongue fluently in the following ways to master phonetics and intonation when using their mother tongue: Children can read expressively, use gestures to supplement spoken language, developed vocabulary and grammatical structure. Common linguistic features in 5-year-old children are explanatory language, children have a need to receive explanations and also like to explain to friends. In addition, children experience situational language by communicating with people around them with information that they directly perceive in the scene.

Clear coherence: because children's vocabulary accounts for $50 \%$ of nouns, their sentences are often short and clear. However, the locality in the language of the local culture, the community is evident in the child's language (slurred speech, lost accent...), the individuality has been clearly revealed through other nuances of children, especially in expressive language function. The use of language in communication and the properties of language in children depend largely on the guidance and verbal example of adults.

\subsubsection{The development of cognitive processes of 3 to 5 year-old children}

Psychological phenomena such as perception, memory, and imagination are basically the continuation of the development at the age of $4-5$ years old, but the quality is newer. The richness of the types, the degree of intention, the psychological processes are clearer, more conscious, the purposefulness of formation and development is at a higher level. The sensitivity of the senses is more refined. The ability to control psychological reactions is developed.

Here we only refer to the most powerful and characteristic developmental psychological process, which is thinking. The development of thinking at this age is strong in types, operations and the rapid establishment of relationships between events, phenomena, information between new and old, near and far... 
General characteristics of the development of thinking: children know how to synthesize not only objects, images but even words. Children's thinking gradually loses its selfishness and moves towards being more objective and realistic. Gradually, children learn to distinguish between reality and fiction. Children have abstract thinking with numbers, space, time, social relations...

Children are aware of their thoughts, feelings, and responsibility for their behavior. The qualities of thinking have revealed enough about its structure and function such as purposefulness, independence, creativity, flexibility, flexibility... In children at this stage, children develop both 3 types of thinking, intuitive action thinking still prevails. However, due to the task of operation, but also the type of visual-visual thinking, abstract thinking is developed in children. This kind of thinking helps children get closer to objective reality.

\subsubsection{The emotional and willpower development of 5-year-old children}

At this age, children develop friendships. Emotional and emotional life is more stable, the level of richness and complexity increases according to communication relationships with people around. Human emotional nuances in relation to different age groups and social positions are formed as:

2.1.5.1 Emotional development

Family affection: the love of mother and child, grandparents, brothers and sisters, affection for teachers, relatives, strangers... develops strongly and deeply. However, the emotional life of children is still fragile. dynamic, situational.

Intellectual affection: Children's intellectual feelings develop, each new perception stimulates children's joy, excitement, fascination; curious curiosity, giving rise to many positive emotions; In play, learning, self-service, many successes and failures reinforce emotional and intellectual development in children.

Moral sentiment: By understanding the meaning of good and bad behavioral standards. Through fun communicating with people; due to the good lifestyle habits built by families, kindergartens... Children are aware of many good behaviors that need to be performed to please everyone.

Aesthetic feelings: Through classes in visual arts, music, learning about the surrounding environment... Along with the perception of natural beauty, harmony of layout, arrangement in family and class learn. Children have a clear sense of beauty and ugliness according to the standard (at first, according to the child's standards, gradually in accordance with the evaluation of the people around) aesthetic feelings, developed aesthetic sense.

\section{ISSN 2455-6378}

\subsubsection{Willpower development}

Due to the ability to master many behaviors, being assigned many small tasks by adults.. Children gradually have clearly identified the purpose of actions. Children gradually separate motivation from purpose with trying to complete the task.

Children want to play games, hear more stories but are not met by the teacher, have to change games that children do not like.

The purpose of the child is more and more aware of and tries to complete the work. The love of planning appears, the child knows how to arrange "work" and play, and has to sweep the house, pick up vegetables so that when the mother comes back, everything must be done. for mother satisfaction.

Self-responsibility is gradually formed in children. The development of strong or weak will depends largely on the education and educational measures of parents, teachers and surrounding adults.

\subsubsection{The identification of ego-consciousness}

The premise of ego-consciousness is the separation of self from others, which has been established since the end of the age of 2. However, it takes a development process for the child's sense of self to be clearly defined. At the age of 5, children understand how they are, what qualities they have, how people around them treat them, and why they have this or that action... a sense of self. This is most evident in our self-assessment of our successes and failures, our strengths and our weaknesses, our abilities and our inability.

In order to properly evaluate himself, the child must first learn to judge others and hear how those around him judge him or herself. At first, the child's evaluation of others depends a lot on his attitude. its degree to this person. For example, every child thinks his mother is always good. At this age, children master the skill of comparing themselves with others, this is the basis for a more correct selfassessment and also the basis for imitating good people, good deeds, self-awareness. It is also evident in the sexual development of children. Children not only realize that they are a boy or a girl, but also know if they are a boy or a girl, how this behavior must be expressed in accordance with their gender.

Ego-consciousness is clearly defined to help children control and adjust their behavior gradually in accordance with social norms and rules, from which children's behavior is social. Being clearly defined also allows children to take more deliberate actions. As a result, psychological processes are clearly intentional.

\subsection{Favorable psychological characteristics of preschool children when learning English as a second language}


Scientific studies have shown that: from 3 to 5 years old (kindergarten) is the "golden" period of language development. Many language experts also assert that it is too late to wait for a 7-year-old child to learn English. Accordingly, the period of 3-5 years is the ideal time for children to learn English for preschool children.

According to research by psychologist Dr. Elaine Schneider - a child language expert in the US, children are exposed to English as early as possible. Because according to her, the brain of young children, especially those from one to five years old, is like a sponge that can absorb information around them very quickly and quickly. Besides, the structure of the organs of hearing and pronunciation in young children at this stage also makes it easier for them to imitate different pronunciations.

According to research by educational psychologists at Ho Chi Minh City University of Education: from 20 months to eight years old is the period when young children develop the strongest language. language sensibilities". If children are facilitated to learn a second language in parallel with their mother tongue, they will not only promote their language ability but also have more logical thinking ability when they grow up.

At the age of 5, children have the highest ability to learn language; Learning content should be designed to be simple, easy to understand, with a focus, and must be suitable for children's perception, balancing the curriculum at school and life. This will make your child feel comfortable when participating in classes and naturally approach English like his or her mother tongue. At this time, children learn a foreign language or learn their mother tongue equally easily and quickly. Your baby won't be completely confused between languages as people think.

According to research by psychologists, children's main activity in this period is play activities, so learning through play activities to help children approach English is a way that is suitable with their characteristics. child's psychology. Songs, stories and vocabulary for children to get acquainted with English need to be collected, which must be suitable with the receptive ability and cognitive level of children at each age, set in topics close to their experience. children's experiences and interests. Special attention is paid to the development of listening and speaking skills, strengthening the development of fundamental competencies, necessary qualities and social skills such as sensitivity of the senses, flexibility in thinking. and awareness, confidence in communication and problem solving, creativity, boldness and confidence, dynamism and openness, contributing to improving the quality of comprehensive education, creating a language foundation and Connectivity helps children learn English well in primary school and realize the goal of preschool education in the integration trend.

\section{ISSN 2455-6378}

Learning content: songs and poems for children to get acquainted and learn English towards meeting their needs and promoting their language ability; English language learning carried out in connection with the flexible implementation of the current Pre-school Education Program will contribute to the comprehensive development of the child's personality.

To take advantage of this "golden moment", parents should learn and create the best conditions for children to learn English. Because this is the time to build the first language "bricks" to create a solid "foundation" for the child's future English learning process.

\section{Some suitable methods of teaching and learning English for children's psychological characteristics 3.1 Teach approach in a learner-centered manner}

Foreign Languages was established on the basis of "learner-centered". With many years of experience in teaching many different subjects, being learnercentered is a principle that teachers need to master. The same goes for teaching English to children. When children work to dominate poetry, it is a way to help children retain knowledge longer. In each lesson, children participate in many activities, after each lesson, they are given worksheets to go home to review and consolidate.

In order for young students to increase their concentration when learning English, teachers need to combine their time teaching English to children with movement games, word puzzles, or songs with fun melodies and rhythms. moderate as well as simple words to help children easily memorize and sing along. In addition, when teaching children new vocabulary, teachers should use more diverse and vivid pictures and pictures to create interest in learning. The method of teaching English combined with illustrations will help children easily absorb new words and remember them longer. Moreover, teachers should also create many different situations for children to have the opportunity to show their English. Teachers always help children to be active, brainstorm, surely children will feel extremely excited when participating and thereby stimulating children to be eager to learn more new vocabulary.

\subsection{Create conditions for children to familiarize themselves with English through a variety of activities}

There are many studies on foreign language teaching methods in general and English in particular. Both theory and practice show that for kindergarten children, we cannot apply foreign language teaching methods like adults, but methods for children to 
become familiar with English need to be age appropriate. characteristics of children's psychophysiological and language development. The methods of implementing English familiarization for children need to follow kindergarten pedagogical methods, specifically the method of language development for children. In addition, standard English pronunciation and flexible, appropriate use of English in specific situations are the most vivid visualizations for children to get used to English. According to practical experience, when introducing children to English, it is necessary to note:

- Play rather than teach.

- Activity, more pictures than theory.

- Learning tools are better than textbooks.

- Talk more than listen-write.

- Imitation than grammar.

- More fun for points.

The psycho-physiological characteristics of kindergarten children are "easy to remember - easy to forget", so I have built them to familiarize themselves with English anytime, anywhere, and regularly review to let them remember.In the process of introducing children to English through day-today activities, I personally found that children memorized vocabulary very well. Children are especially excited to express themselves and participate in playing games, singing and exercising English songs.

\subsection{Collecting suitable English songs and stories for children}

Communication is indispensable in daily activities, helping children to be more confident. Therefore, let children get used to self-introduction, health inquiries, answers... so that they will be more confident. In these activities, teachers can combine for children to watch cartoons, use puppets, and play games for you to role-play to practice. In the current information technology era, there are many English songs, songs, stories on entertainment channels, books and newspapers. However, in order to help preschoolers become familiar with English, it is necessary to ensure the following factors: appropriate to the educational content, appropriate to the child's ability and age-appropriate development. New words for children to get used to need to be chosen appropriately, ensuring the rules from easy to difficult, from simple to complex.And especially for kindergarten children, with the teaching method: "Learn to play - Play to learn", English vocabulary needs to be close to children, stick to topics and events for children to feel comfortable, fun to get to know.

For five-year-olds, teachers can choose Story Time course for children to approach English naturally through English stories and songs to equip children with English skills and life skills with practical learning topics.

\subsection{Teaching a combination of bilingualism for children}

The latest studies have shown that introducing bilingual children at an early age will help them be intelligent, flexible in problem-solving, increase concentration, enrich knowledge as well as emotional skills. Many people believe that learning English requires language skills. In fact, there are people who have studied English for more than 10 years but still have difficulty in presenting concise sentences, but there are people who have studied for a few months and can communicate fluently. The cause depends on many factors that affect each learner. However, if you want to be successful in learning a language, determining the content and learning methods suitable for the learner's own ability to receive information will be the first decisive factor. The use of bilingualism in teaching is also a process that helps children turn a second language (English) into a language that is used as often as a mother tongue. It is important that children familiarize themselves with English, which must also be combined with the current preschool teaching program to give children the opportunity to expand their vocabulary and make English more familiar and close in the process. study program. From there, children will receive the new language in the most natural and effective way.

\subsection{Respect children, create excitement for children in communication}

United Nations Convention on the Rights of the Child (UNCRC). Accordingly, children are guaranteed all the rights to protect their body, health and spirit to create a safe, healthy environment and the most comprehensive development for them.

Children need respect, equality in communication, learning opportunities, and safety. If respected and created good conditions, children will develop their language potential well.

For 5-year-old children, interest and learning attitude account for optimal results in learning outcomes. Therefore, the teacher's teaching method and communication skills must be suitable for the child and each individual child... this requires the teacher to be always creative, close, understand and respect children. Encourage and encourage the child, praise the child, do not criticize or punish the child.

In addition, to keep children interested, we can invite foreigners who know English to communicate with children if possible. An important factor to help children acquire knowledge is the person who imparts the knowledge. However, in order to attract children's attention, to meet the 
learning needs, to meet the needs of students' parents, teachers need to invest in lessons, organize activities and games, but to catching up with the trend and meeting all the needs of children is still limited. In the process of teaching children, teachers pay attention to the individual abilities of children, based on the child's development characteristics, based on their own capacity, based on research documents, it is necessary to develop the most flexible and effective specific measures.

Children will become the future owners so helping them to know English and the international arena is a key issue.

\section{Conclusions and Recommendations 4.1. Conclusions}

We all know that English is a global language and the development of foreign languages for children is an issue that needs attention. Foreign languages are also an important condition for their children to access and update knowledge sources from all over the world. Until now, Vietnam as well as some other countries have started to use English more commonly. In the trend of exchange and integration, English has become useful, helping children to confidently communicate and freely explore diverse colors from other cultures.

Research shows that: "Children have the ability to acquire language naturally and especially when they are 5 years old". The best time for children to receive a foreign language and speak like a native at the age of 5 is the "Golden Time" of the child's acquisition. At this time, the child's brain with the most optimal ability to receive and remember information, does not follow any rules. Therefore, when being acquainted with foreign languages from an early age, children's language acquisition ability will be maximized. For children who have the opportunity to learn English as a second language from an early age, when they grow up, they tend to approach other languages naturally and faster. Therefore, developing foreign languages for children from an early age will help create a foundation for children to learn more foreign languages later.

Helping 5-year-olds familiarize themselves with English through a variety of activities in preschool, the research topic is appropriate according to the cognitive ability of children. Letting 5-yearold children familiarize themselves with English ensures the system, continuity and regularity. However, it must ensure the right fit (suitable to the characteristics and cognitive ability of each age), according to the system from easy to difficult, from simple to complex, upholding the principle of childcentered education. At the center, the selection and adjustment of appropriate amounts of knowledge and skills to help children learn English effectively also need to be considered.

\subsection{Recommendations}

\subsubsection{For teachers}

Teachers need to have knowledge, fluency and good use of English, and understand the importance of helping children get used to English to contribute to the comprehensive development of children's personality. Teachers must constantly study to improve their professional qualifications, have knowledge of age psychology, and pedagogical knowledge to handle pedagogical situations well.

Teachers need to have language skills, ageappropriate teaching skills, and necessary pedagogical skills. Know how to organize many games using English, sing and act with English songs, create conditions for children to listen and talk a lot, always find ways to encourage children to use English actively. Regularly research the centers' programs for children to become familiar with English. Have the skills to find open learning materials to teach children effectively. It is necessary to have teamwork skills and communication skills to closely combine family and school in teaching children to learn English.

In teaching and communicating, it is necessary to respect children, listen to children, learn and absorb ideas to meet children's needs and ensure that they are suitable for children's development. Teachers always have a positive attitude, create a joyful and comfortable atmosphere for children, encourage children to attend school regularly, pay attention to shy children, and create the best conditions for children to boldly and confidently participate in group activities, help children communicate more.

\subsubsection{For parents:}

Parents should be bold and prepare the best mentality for children to approach, get acquainted and learn English when children are 5 years old, know how to support children to be confident in communication, trust in the care and teaching of teachers. pellets. Especially change children's conception of learning English, consider this an important skill that children need to practice during this period. Parents are also the first teachers of children, so parents need to learn. appropriate ways to care and educate children, so that children develop their outstanding potential. Nurturing, caring and protecting children is the most important responsibility of parents.

\subsubsection{For educational administrators, educational institutions}

Educational administrators need to realize that the quality of a comprehensive education is to create the best opportunities for children. In addition, it is necessary to plan support policies for children: 
develop reasonable program content, invest in specialized teachers, and provide facilities for English teaching activities.

\section{References}

[1] HoàngAnh, NguyễnThanhBình, Vũ Kim Thanh (2004). Course book of Communication Psychology, Hanoi Pedagogical University Publishing House. Vietnam

[2] HoàngAnh (2007). Activities Communication - Personality. Hanoi Pedagogical University Publishing House. Vietnam.

[3] Ministry of Education and Training, Department of Teachers (1992) Some psychological issues in pedagogical communication, Hanoi.

[4] Ministry of Education and Training (2010). Circular promulgating regulations on the development standards of five-year-old children.

[5] A.G. Covaliov (1971), Personal Psychology, Vol. 1,2. Education Publishing House. Hanoi. A.G. Covaliov (1976), Social psychology. Education publisher. Hanoi. E.I.Chikhiepva (1975), Language development of preschool children, Education Publishing House, Hanoi.

[6] Alderson, J. C., Clapham, C. and Wall, D. 1995. Language Test Construction and Evaluation. Cambridge: Cambridge University Press.

[7] Anastasi, A. 1988. Psychological Testing (6th ed.).New York: Macmillan.

[8] Bachman, L. F. 1990. Fundamental Considerations in Language Testing. Oxford: Oxford University Press.

[9] Bachman, L. F. and Palmer, A. S. 1996. Language Testing in Practice: Designing and Developing Useful Language Tests. Oxford: Oxford University Press.

\section{ISSN 2455-6378}

[10]Broughton, G. \&Brumfit, C. 1978. Language in Education: TestingtheTests. Newbury House.

[11]Cameron, L.2001. Teaching Language to Young Learners. Cambridge: Cambridge University Press.

[12]Doff, A. 1988. Teaching English: Trainer's Handbook. Cambridge: Cambridge University Press.

[13]E.A. Grebensicôva (1968), Kindergarten teacher, Education Publishing House.

[14] Grounlund, N.E. 1985. Measurement and Evaluation in Teaching. Englewood Cliff: Prentice Hall.

[15] Harrison, G. W., 1986. An experimental test for risk aversion. In Economics Letters, Elsevier, vol. 21(1), pages 7-11

[16] Mac Van Trang (2007). Children with learning difficulties - an urgent problem that needs to be studied and solved. Journal of Psychology, 6 (99), p24-27.

[17] NguyễnCôngKhanh (editor) ĐàoThịOanh(2016). Examination and assessment curriculum in education. Pedagogical University Publishing House.

[18] Nguyen Quang Uan (2010). Collection of research on Psychology - Education. University of Education Publisher.

[19]Rajagopalan, I. (2019). Concept of Teaching. Shanlax International Journal of Education, $\quad 7(2)$, 5-8. https://doi.org/10.34293/education.v7i2.329

[20]Roser, M. (2017). Teachers and Professors. Published online at OurWorldInData.org. Retrieved from https://ourworldindata.org/teachers-and-prof essors.

[21] Schreier, D., Hundt, M., \& Schneider, E. W. (2019). World Englishes: An Introduction. The Cambridge Handbook of World Englishes, 1-22. doi:10.1017/9781108349406.001

[22] Sequeira, A. H. (2012). Introduction to concepts of Teaching and Learning. SSRN. 